\title{
Home food making, belonging, and identity negotiation in Belgian Taiwanese immigrant women's everyday food practices
}

\author{
Hsien-Ming Lin ${ }^{1,2^{*}}$, Ching Lin Pang ${ }^{3}$ and Da-Chi Liao ${ }^{4}$
}

\begin{abstract}
This article examines the experiences of (re)producing home food in the daily life and food practices of Belgian Taiwanese immigrant women. The research is based on ethnography_both online and offline-and qualitative semistructured interviews with seventeen Taiwanese immigrant women/housewives in Belgium. Participants' food practices involve buying, growing, making, and sharing food. Buying Taiwanese food ingredients presents a genuine challenge, as Chinese and Asian supermarkets in Belgium do not carry all Taiwanese food items. Consequently, many Taiwanese immigrant women and housewives in this study share similar experiences of growing specific foods in their home garden; moreover, by doing so, they also transform their gardens in their private homes into transnational social spaces, and thereby connect their previous lived experiences and homeland memories with their present living circumstances. Moreover, Taiwanese immigrant women like to prepare and cook food with their husband and children while imparting Taiwanese food and cultural values through personal stories. Furthermore, by organizing and regularly participating in activities involving sharing and eating food with other Taiwanese immigrant women, these foodsharing events and behaviors also become an important social networking strategy that allows them to make, expand, and cultivate friendships; in addition, food sharing activities also assist the participants to construct a collective social identity of being immigrant mothers/housewives in a foreign land. However, what is meant by "Taiwanese" food varies substantially between participants, as do the associated emotional and ethnic meanings. Several things were stated to account for the taste of Taiwanese food, such as using certain condiments or the Ta Tung rice cooker. Equally diverse is the personal attachment of ethnonational identity toward the notion of home food, as discussions of childhood memories, ethnonational identity negotiation, and cultural markers are accompanied by critical reflection on the social constructed nature of home/ethnic foods in the migration contexts.
\end{abstract}

Keywords: Belgium, Cuisine culture, Ethnonational identity, Food practices, Taiwanese immigrant community

\section{Introduction}

In this study, the authors take Taiwanese immigrant women in Belgium as the research subject, examining their daily food practices and experiences of making home/ethnic foods while living in a foreign land. Their

\footnotetext{
* Correspondence: hsienming.lin@student.kuleuven.be

${ }^{1}$ Faculty of Social Science, Katholieke Universiteit Leuven, Leuven, Belgium ${ }^{2}$ Institute of Political Science, National Sun Yat-sen University, Kaohsiung, Taiwan

Full list of author information is available at the end of the article
}

subjective meaning-making regarding home foods, especially in the immigrant context, is also explored.

Why is making or eating home foods important for immigrants? Many scholars have tried to explain the role that home/ethnic foods play in immigrants' international movement and adjustment journeys. Ore pointed out that consuming home/ethnic foods makes several positive impacts on immigrants. The behavior of eating home/ethnic foods not only provides immigrants with

(c) The Author(s). 2020 Open Access This article is licensed under a Creative Commons Attribution 4.0 International License, which permits use, sharing, adaptation, distribution and reproduction in any medium or format, as long as you give

appropriate credit to the original author(s) and the source, provide a link to the Creative Commons licence, and indicate if changes were made. The images or other third party material in this article are included in the article's Creative Commons licence, unless indicated otherwise in a credit line to the material. If material is not included in the article's Creative Commons licence and your intended use is not permitted by statutory regulation or exceeds the permitted use, you will need to obtain permission directly from the copyright holder. To view a copy of this licence, visit http://creativecommons.org/licenses/by/4.0/. 
necessary nutrition; the tastes of home/ethnic foods can also further release and decrease the emotions of nostalgia. In this regard, immigrants refer to foods derived from their home country as "comfort foods" in their foreign life, since these foods provide positive psychological effects and further improve people's wellbeing. Compared with people who live in their home country, immigrants may face far more challenges and difficulties when making their home/ethnic foods in their migrant life, since it is often difficult to find all of the food ingredients they need in the host society [1]. Moreover, Gu further pointed out that in most intercultural marriages and mixed-culture families, Asian immigrant women take on the majority of the responsibility, including domestic work, raising children, caregiving, and preparing food for the family on a daily basis. Thus, arranging family's daily diet and, in the process, balancing the different taste preferences among family members are two of the vital tasks for immigrant women, especially in intercultural or mixed-culture families [2]. However, living in different cultural contexts, people may have distinct cuisine cultures, taste preferences, and food systems. Thus, balancing different taste preferences and arranging daily food menus in intercultural spousal relations and mixed-culture families is not an easy process. However, the process does not only involve a series of negotiation and communication procedures between/among family members; as Bove et al. already pointed out, Asian immigrant women take on the majority of domestic and family food arrangement work in the migration context, as well as in mixed-culture families, meaning that immigrant women may experience more pressures than their western spouses (in most cases, western men) regarding this issues [3]. This is the reason why D'Sylva and Beagan indicated that daily food arrangements and the negotiation of different tastes in intercultural spousal relations could be regarded as the reflection of immigrant women's position and its power hierarchy within the family. Moreover, these authors noted that immigrant women's family and power position could be demonstrated through the consequences of whether their family members accept the foods cooked by their immigrant family members, especially when these foods are prepared and presented on the family's dining table [4].

Accordingly, immigrant women not only play vital roles in their family's daily diet and food arrangements, but also face more difficulties related to cooking and consuming their home/ethnic foods in the daily food practices than their western and homeland counterparts. These difficulties and challenges may further result in some negative emotional impacts $[5,6]$. In this regard, since immigrant women do play special roles as regards their family's daily food and diet arrangements, Seto-Suh noted that scholars should pay more attention on applying gendered and women's perspectives when examining the role played by home/ethnic foods during immigrants' international movement and adjustment journeys [7]. The abovementioned discussions provide strong support to authors in the present study of the reason why we take Taiwanese immigrant women in Belgium as the research subject and examine their daily home/ethnic foods practices, as well as other related issues regarding their sense of belonging, the ethnonational identity negotiation, and homemaking experiences.

\section{Home/ethnic foods in the migration context: belonging, identity, and homemaking}

In this section, the authors will discuss the notion of home/ethnic foods and other related dimensions regarding belonging, identity, and homemaking, particularly in the migration context. In terms of the relations between home/ethnic foods and the sense of belonging in immigrant life, Vignolles and Pichon found that eating home and ethnic foods can successfully reduce immigrants' sense of loss and up-rootedness and further enhancing their sense of belonging toward their host society and immigrant life [8]. Gunew further argued that consuming home/ethnic foods is a crucial strategy adopted by immigrants to connect their previous life with their present one [9]. Moreover, Duruz indicated that people may attach their sense of belonging to, or even construct place-identity with, a particular place or space by utilizing specific foods as their linkages or references [10]. For example, many Taiwanese people construct some part of their "Taiwanese identity" or show their "Taiwanese" ethnicity by drinking the world-wide famous Taiwanese beverage of "bubble teas" (zhēn zhū năi chá, 珍珠奶茶) since these beverages already have been regarded as one of the important compositions that constituted the "Taiwanese" cuisine culture [11]. Moreover, from the viewpoint of social identity theory, home/ethnic foods are vital resources and references used by people in delineating the ethnic boundaries that ethnically distinguish between "us" and "others," since different ethnic groups have their own special food cuisine cultures and food consumption habits. In this regard, for some people, eating home and ethnic foods have become the strategy for performing their ethnicity or social group identity [12]. However, as noted above, immigrants may face more difficulties and challenges when making and eating home/ethnic foods compared with their local counterparts in the host society. Thus, Weller and Turkon applied the perspective of Tse to examine how different living circumstances in the host society may further influence immigrants' willingness and attitudes toward making and eating their home/ethnic foods in a foreign land. These authors found that when immigrants face discrimination in the host society due to their 
immigrant or ethnic minority backgrounds, immigrants may increase the possibility of choosing the "downplaying" strategy to decrease the importance of their ethnic characteristics, for example, by insisting on speaking the host society's local language in front of others rather their mother tongue. This downplaying strategy may further lower immigrants' willingness to consume home/ ethnic foods in their immigrant life. This means that different living circumstances and the level of local residents' tolerance regarding cultural/ethnic differences and immigrant groups both have further and different impacts on immigrants' attitude toward their own cultures, ethnic backgrounds, and food consumption habits $[13,14]$.

In addition, some studies have attempted to examine the roles that home/ethnic foods play in immigrants' homemaking experiences. For example, Schermuly and Forbes-Mewett found that many immigrants consider sharing traditional or ethnic foods from their home country with friends or neighbors in the host society to be a useful strategy for expanding their social networks and cultivating interpersonal relations in their immigrant life. This means that home/ethnic foods have become useful tools used by immigrants to cultivate and manage their friendships and social networks in the host society, since foreigners may face more difficulties than their local counterparts in meeting new people and making new friends [15]. Moreover, Liu and Pang argued that in immigrants' homemaking processes, home/ethnic foods have a double-sided effect: on the one hand, these foods can assist immigrants to connect their previous and present life experiences, while on the other hand, eating and consuming home/ethnic foods can further help immigrants to construct their new place-identity and sense of belonging in the host society. They took pan-Chinese immigrant women living in Antwerp as the research subject and examined what consuming traditional Chinese and home foods meant to them during their lives in Belgium. Their findings suggested that eating Chinese ethnic/home foods in daily life make these Chinese immigrant women obtain the "home feelings," letting them feel that they are "being at home" even though they have already left their home countries, and lived in the foreign land of Belgium for years. In addition, by preparing and eating Chinese foods with their Belgian family members and children, the family food arrangements and home/ ethnic foods consumption practices not only increase their personal identity of being an immigrant mother in the host society, but also help them to regard Belgium as their "home" rather than a temporary living place [16].

The above discussions have demonstrated several important aspects. Firstly, the meanings of "home food" for people are not static but dynamic; when people's living circumstances change, the meanings of home food for them may also change. Thus, the meanings and functions of home food for immigrants go beyond its status as food and necessary nutrition, however, further encompass some other social and emotional functions. Moreover, the above discussions also reveal the special role played by immigrant women in mixed-culture families, especially in terms of everyday and family food arrangements. In addition, we aim to fill the research gap regarding the Taiwanese immigrant community in Belgium, while considering the fact that immigrant women do constitute the majority in this minority community. Thus, in this study, the authors choose Taiwanese immigrant women in Belgium as the research subject, examining their home food practices in the daily life while living in a foreign land and the meanings ascribed to home food in the migration context. It is important to note here that the definition of food practice in this article encompasses any kind of activity in which food is involved. Before entering into the discussion regarding the Taiwanese immigrant community in Belgium, in the next section, the authors will further review and discuss cuisine cultures in Taiwan, particularly through the lens of ethnicity.

\section{Ethnicity and cuisine culture in Taiwan}

There are 23 million people living in Taiwan today. Compared with its East Asian neighbors (e.g., mainland China, Japan, or South Korea), Taiwan has a moderate level of residential population. Within this moderate population, Taiwanese society comprises at least five major ethnic groups. The largest two ethnic groups in Taiwan are Holo (tái wān mǐn nán rén, 臺灣閩南人) and Hakka (tái wān kè jiā rén, 臺灣客家人). The ancestors of both of these two ethnic groups mainly emigrated from the south-east parts of mainland China to Taiwan, beginning from the late seventeenth century. In contemporary Taiwan, the Holo population exceeds 15 million, while there are about five million Hakka living in Taiwan. In addition to these two ethnic groups, Taiwan is also home to groups of its aboriginal people (tái wān yuán zhù mín, 臺灣原住民); however, the aboriginals are in fact constituted by 16 sub-ethnic groups, with half million of populations in total, who mainly reside in the mountain areas of Taiwan. Moreover, Taiwan is home to another ethnic group, namely as the mainlanders (wài shěng rén, 外省人). They primarily emigrated from mainland China to Taiwan in the late 1940s and early 1950s; this was due to the fact that, at that time, the Kuomintang (KMT) government and its troops lost the civil war they were fighting with the Chinese Communist Party (CCP). Because of this loss, the KMT government brought millions of mainland Chinese people and its soldiers emigrated from mainland China to Taiwan. According to statistics, in the late 1990s, there were about 
2.5 million mainlanders living in Taiwan. Furthermore, the emerging (and ethnically diverse) group in Taiwan is the new immigrants (xīn zhù mín, 新住民). Most of them came from mainland China, while others come from South-east Asia, mostly via the intercultural marriages that began in the late 1990s. At that time, Taiwan had experienced decades of rapid economic growth and magnificent economic development. Consequently, the advantageous economic conditions in Taiwan became an important pull factor that attracted large numbers of women to immigrate to Taiwan and marry Taiwanese men. Now, there are more than a million newly arrived immigrants living in Taiwan, the majority of whom came from mainland China, Vietnam, Indonesia, Thailand, and the Philippines [17, 18].

Taiwanese society comprises multiple ethnic groups from different places, since they have their own cuisine cultures and food systems, in this regard, making Taiwan's cuisine culture and food systems have become more diverse. Moreover, the question of which ethnic group's cuisine and foods could represent Taiwan has become both an interesting but a controversial one, since it influenced by how people in Taiwan identify themselves, as well as the long-term ethnonational identity changes and developments in Taiwan over the past two decades.

In the past 20 years, the issue of ethnonational identity in Taiwan has undergone a significant change. According to the National Chengchi University's Taiwanese ethnonational identity panel survey, in 1992, $25.5 \%$ of people in Taiwan identified themselves as "Chinese" $(\mathrm{z}-$ hōng guó rén, 中國人); however, this figure decreased to merely $3.5 \%$ in 2018 . On the contrary, in 1992, merely $17.6 \%$ of people in Taiwan considered themselves "Taiwanese" (tái wān rén, 臺灣人); however, this figure increased to $55.8 \%$ in 2018. It is also interesting to note that in 1992, 46.4\% of people in Taiwan had dual ethnonational identity and further regarded themselves as both "Taiwanese and Chinese" (shì zhōng guó rén, yě shì tái wān rén, 是中國人, 也是臺灣人); however, in 2018, this figure further decreased to $37.2 \%$ [19].

The changes and developments of ethnonational identity in Taiwan over the past two decades reveal two facts. Firstly, people in Taiwan have experienced quite serious struggles with regard to the issues about how to identify themselves. Secondly, it is clear that the "Chinese" ethnonational identity label is a less and less popular option for the people in Taiwan, however, with more and more people regarding themselves as "Taiwanese" rather than "Chinese." Moreover, the above ethnonational identity changes also further influence how people, as well as different government administrations, evaluate the values and meanings of distinct cuisine cultures among different ethnic groups. After the KMT government lost the civil war it fought with the CCP, Taiwan's society experienced a long period of KMT's governance between 1949 and 2000. During this period, since the power of central government has had been majorly controlled by the mainlanders, in this regard, traditional Taiwanese cuisines were regarded as low-end foods, and belonging to the level of street vendors, rather than official or wellregarded foods. Accordingly, traditional Taiwanese foods were never included into state banquet menus at that time; by contrast, mainlanders' foods (wài shěng cài, 外 省菜) were considered as an official and high-class cuisine culture. However, the situation changed significantly in 2000, when the Taiwanese opposition party-the Democratic Progressive Party (DPP) - firstly took the power of the central government; this also was the first change in the ruling party in Taiwan's central government since 1949. It is worth mentioning that the DPP was established by a democratic social movement in the late $1980 \mathrm{~s}$, and most of the party members at that time were local politicians or active participants in grassroots politics. Consequently, the party's members and politicians had stronger local and Taiwanese ethnonational identity. This is quite different from its counterpart, the KMT, which was at the time dominated by party members or politicians majorly from mainland China or their descendants; since they had deeper personal and historical linkages with mainland China, thereby, they were more likely to embrace Chinese culture or the ethnonational identity label of being Chinese. Accordingly, once the DPP and its members first took power in 2000, they began to implement a series of localization policies. During the presidency of Chen Shui-Bian (from 2000 to 2008), the president devoted significant effort to improving the image of traditional Taiwanese foods and cuisines and their position in the society's cultural hierarchy. He was also the first president to incorporate Taiwanese foods into state banquet menus. For example, Chen's administration replaced one traditional Chinese and representative mainland dish, Yang-chow fried noodles (yáng zhōu chăo fàn, 揚州炒飯), with the traditional Taiwanese dish wăn gāo (碗糕) on the state banquet menu. By doing so, Chen and his government expected to elevate the image of traditional Taiwanese foods from the street to the official level, as well as to strengthen the Taiwanese people's sense of pride and confidence in their own cuisine culture [20].

In summary, the discussion above has demonstrated that, firstly, no single ethnic food or cuisine culture could entirely represent the food systems and cuisine cultures in Taiwan, since Taiwanese society is constituted by multiple ethnicities of people from different places. Secondly, Taiwanese society has not only experienced significant changes in its notion of ethnonational identity, but also how people in Taiwan identify 
themselves, as well as how people evaluate and perceive the values and meanings of food systems and cuisine cultures among different ethnic groups. In this regard, in Taiwan, people with different ethnic backgrounds may have distinct perceptions or interpretations regarding questions about what "Taiwanese" and "home" foods mean for them.

\section{Taiwanese immigrant communities: worldwide and in Belgium}

In this section, the authors provide further details of Taiwanese immigrants' demographic background information, both around the world generally and in Belgium in particular. According to statistical data from the Taiwanese government's Overseas Community Affairs Council (OCAC), in 2017, there were 1.97 million Taiwanese immigrants living overseas. With more than half of them (nearly one million) having emigrated and taken up residence in the USA, the USA has become the most popular emigration destination for Taiwanese. By contrast, Europe is a less traditional and famous immigration destination for the Taiwanese: only about 45,000 Taiwanese immigrants live in the entirety of Europe. Among the twentyseven European Union (EU) member countries, France has attracted the majority of the Taiwanese immigrant populations, with about 10,000 Taiwanese immigrants living in France. Moreover, 6000 live in the UK, nearly 5000 live in Germany, and 3000 live in the Netherlands, while Austria and Spain have attracted about 1000 Taiwanese immigrants, respectively. In short, Taiwanese immigrant communities in EU member countries tend to be relatively small; only $2.3 \%$ of the total population of Taiwanese immigrants live in Europe [21].

For its part, Belgium is home to only several hundred Taiwanese immigrants. In 1981, 609 Taiwanese immigrants lived in Belgium; in 1990, however, this number decreased to 575, then further decreased to 371 in 2006. However, based on the statistical data announced by the Taipei Representative Office in the EU and Belgium, in 2017, there were about 400 Taiwanese immigrants lived in Belgium [22-24]. It is also important to note that Taiwanese immigrants only account for $0.033 \%$ of Belgian's total immigrant population, as more than 1.2 million international immigrants live in the country [25]. In this regard, because the Belgian Taiwanese immigrants are few in number and small in terms of their ethnic community scale, Pang applied the term "invisible" to describe the Taiwanese immigrant community's social status in Belgian mainstream society. Pang also indicated that the Belgian Taiwanese immigrant community has been ignored and under-represented in the mass media, immigrant policy debates, educational issues, the mainstream labor market, and academic research [23, 26]. Thus, Lin proposed that it is urgently necessary to explore Belgian Taiwanese immigrants' lived experiences and other related topics in order to fill the existing research gap and improve the status of the "invisible" social and academic positions in which Taiwanese immigrants are situated [22].

Moreover, despite its small scale, it is not appropriate to regard the Belgian Taiwanese immigrant community is homogeneous. The argument is borne out by the first author's 3 years (2017-2020) of fieldwork and participant observation experiences in this immigrant community. In fact, the Belgian Taiwanese community is heterogenous if considering individual immigrants' distinct migration trajectories and living circumstances. It is therefore important to point out that, due to the limitations of the annual and official demographic data regarding the Taiwanese immigrant community published by the Belgian government, the sub-group categories presented here are mainly drawn from the first author's 3 years' of fieldwork and his personal experiences of interacting with the immigrant community.

First, taking the timescale into account, the earliest Taiwanese immigrants from Taiwan to Belgium could be traced back to the 1970s. At the time, the majority of them arrived in Europe, and especially in Belgium initially, with the student visas; this means that their primary reason for coming to Belgium was for educational purposes. In the first author's fieldwork experience, he met several elderly immigrants who had emigrated to Europe and Belgium during this time; they mainly studied with majors in French, business, or other European languages. After they completed their college or university degrees and achieved the educational objectives, many of them were attracted by the higher salary levels and better labor conditions in Belgium and decided to stay, since Taiwan at the time was still an agricultural society and people could only earn very limited income through agricultural work. Accordingly, economic considerations were the main push factor that prompted these Taiwanese people to decide to stay in Belgium in order to search for a better life and personal career development opportunities. One very interesting factor is that the majority of these immigrants entered the catering industry and worked in Chinese restaurants. However, at the very beginning, they did not purchase and operate their own restaurants since they lacked the investment money. Thus, many of them worked as hourlywage earners (打工仔) at Chinese restaurants that were mainly operated by mainland Chinese immigrants. In fact, the first Chinese restaurant in Belgium was opened in 1923 in the city of Antwerp and operated by early immigrants from mainland China. The pan-Chinese catering industry has a long developmental history in Belgium, and there were many Chinese restaurants spread all over the country rather than being 
concentrated on specific areas or cities; these were all advantageous conditions for Taiwanese immigrants in the 70s, as it made easier for them to find part-time or full-time positions in the industry. Many of the first author's research participants followed this emigration trajectory and work pathway, which allowed them to successfully earn enough investment money after several years' hard work as hourly wage earners. After that, many of them decided to invest and operate their own restaurants rather than working for others. But why did most of the Taiwanese immigrants at the time choose to enter the catering industry? The study conducted by Pang provides some possible explanations. Based on her calculations, people only needed to invest about 500,000 Belgian francs-equivalent to 12,500 euros-so as to have their own restaurant in the 1970s. Moreover, she found that the cost of investing in a restaurant in the Chinese catering industry was the lowest-cost entrepreneurial activity for the pan-Chinese and Taiwanese immigrants at the time compared with investing in other sectors of the economy [23]. Moreover, restaurants in the Chinese catering industry are mainly run by immigrant couples and/or their family members. Thus, the low-cost and family-oriented natures of this business, therefore, attracted plenty of pan-Chinese immigrants joined into the industry [27].

However, the largest subgroup within the Taiwanese immigrant community in Belgium, in fact, is majorly constituted by the Taiwanese women and housewives. Based on the first author's fieldwork experiences and participant observations, immigrant women and housewives account for about $70 \%$ of the Belgian Taiwanese community, since the majority of them immigrated to Belgium mainly via the trajectory of intercultural marriages and romances. Unlike the previous subgroup of early Taiwanese immigrants, who mostly emigrated to Belgium in the 1970s, these Taiwanese immigrant women did not migrate in a specific period of time. However, many of them were limited by their visa type (Dependent Visa, Visa D) and lack of local language proficiency, since in Belgium, the major local languages are Dutch and French, but most of these Taiwanese immigrant women could only speak Mandarin Chinese and English. The above limitations had further negative impacts on those Taiwanese immigrant women, making it difficult for them to find an official or permanent job in the mainstream Belgian labor market. In this regard, many of them had no choice but to become fulltime housewives, consequently taking the majority of responsibility for domestic work, caring for children, and their family's daily food and dietary arrangements. Thus, Gu utilized a term of "housewifeization" (jiā tíng zhǔ fù huà, 家庭主婦化) to describe the process by which the Taiwanese immigrant women experienced the transformation from job-holding/professional women to full-time housewives [28]. As this subgroup constituted the majority of the Taiwanese immigrant community in Belgium, the authors chose them as the research subject in the present study.

Moreover, facilitated by the rapid development of globalization and international business expansion since the 1990s, the trajectories of emigrating from Taiwan to Belgium become more diverse. One of the obvious migration flows from Taiwan to Belgium is that there has more and more highly skilled migrant workers and professional expatriates left Taiwan and chose to work and live in Belgium. The majority of them are hired and working at multi-national companies in high-tech industries, particularly in the semi-conductor sectors, since Taiwan is famous for its high-tech production, Information and Communications Technology (ICT), and semiconductor industries. Moreover, many Taiwanese hightech companies have established long-standing cooperative relations with their European and Belgian high-tech industry counterparts; these mutually cooperative relationships provided a new immigration channel for highskilled and professional Taiwanese workers, giving them opportunities to leave Taiwan and work in Belgium. It is however important to note that most of these positions are offered on a temporary basis; the average length of stay in Belgium is about 3 to 4 years, and the majority of these immigrants are 25-40 years of age [29]. Furthermore, the latest trajectory for Taiwanese immigration to Belgium is via the Working Holiday program established between the Belgian and Taiwanese governments. In 2013, the Belgian government signed a working holiday contract with the Taiwanese government, announcing that they had opened their working holiday visas and markets to young Taiwanese people aged between 18 and 30 with a quota of 200 per year. By participating in this program, young Taiwanese working holiday workers are allowed to work and live in Belgium for a maximum of one year [30,31]. Both of these two subgroups are temporary migrants due to the limitations of their visa types; accordingly, neither of them will not be taken into consideration in this study. However, it is important to point out that some Taiwanese immigrants in these two subgroups later become permanent immigrants who decide to work and live in Belgium for a long period of time, since they may marry locals or obtain a full-time position in the host society.

Accordingly, it should be considered that immigrant women do play a special and critical role in intercultural spousal relations, food, and diet arrangements in mixedculture families, and moreover, that immigrant women and housewives constitute the majority of the Taiwanese immigrant community in Belgium. This study therefore takes Belgian Taiwanese immigrant women/housewives as the research subject and aims to examine their home/ 
ethnic food making, consumption, and other food practice experiences in their daily life, as well as to further explore some other related research topics regarding a sense of belonging and ethnonational identity negotiation via the lens of various home/ethnic foods practices.

\section{Methodology: online and offline ethnography}

This study aims to investigate Taiwanese immigrant women's home/ethnic foods making, eating, and other practice behaviors in daily life rather than the statistical relations between different variables. Accordingly, the authors choose to apply the ethnographic approach to collect research data and the interpretive approach to conduct the further analysis. The authors put the ethnographic method of data collection into practice by utilizing both the online and offline ethnography methods, along with semi-structured interviews to collect the research data.

The procedures utilized by the authors to conduct the online ethnography data collection will be discussed first. In fact, before the first author successfully entered into the Belgian Taiwanese immigrant communities' social activities, he utilized social media to access this immigrant community. The first author conducted years of online participant observations and online fieldwork on several Belgian Taiwanese immigrant virtual communities on Facebook, including the “Taiwanese in Belgium”(台灣人 在比利時), “Taiwanese Wife/Husband in Belgium”(台灣 媳婦(女婿)@比利時), and “Belgian Taiwanese Immigrant Wives Chat forum” (比國主婦哈拉543). The aim of doing the online participant observations was to explore online users' social and interpersonal interactions and communication behaviors on the virtual communities. Moreover, based on the online ethnography research method, the authors applied several online qualitative research methods to collect research data, including online participant observations and online interviews via email and instant message chat [32-35]. However, as online and offline are two sides of the coin, and peoples' online and offline lives are in reality inseparable, it is not enough to merely take peoples' online lives into consideration. Thus, in order to explore Taiwanese immigrant women's offline life and home/ethnic food practice behaviors, the first author further conducted offline ethnography fieldwork and participant observation through working as a Chinese language teacher at the heritage school of "Ecole Sun Yat-Sen" (布 魯塞爾中山學校) in Brussels every weekend. It is worth noting that the school is the oldest Chinese heritage school in all of Europe and was established in 1965 by immigrants from Taiwan. Moreover, the school still receives the majority of its financial support from the Taiwanese government. Since all of the administrative staff and teachers at the school are Taiwanese immigrants, and mostly Taiwanese immigrant women, the school has become one of the main gathering places for the Taiwanese immigrant community in Belgium [36]. Furthermore, being the Chinese language teacher at the school further provided the first author with plenty of opportunities to access and interact with these Taiwanese immigrant women and language teachers.

Through simultaneously conducting fieldwork online and offline, the present study successfully recruited and interviewed 17 Taiwanese immigrant women and housewives. Regarding the sampling method, the authors applied both purposive sampling and snowball sampling strategies to find and invite the research participants. The main selection criteria were Taiwanese immigrant women, who have already immigrated, who have lived in Belgium for more than 1 year, and who have long-term settlement goals and live plan in Belgium. Regarding the semi-structured interview process, all interviews were conducted in Mandarin Chinese. Each interview lasted for 1 to $1.5 \mathrm{~h}$; moreover, with authorization from interviewees, the first author used pen recording to record the contents of each interview, after which the first author fully transcribed for further analysis. Interviews were held at places or spaces chosen by the participants, such as interviewees' private homes, coffee shops, restaurants, the language school, and so on. In order to ensure anonymity and confidentiality, all research participants were designated by a code made up of the letter $\mathrm{P}$ and a number (e.g., P1, P2...); here, "P" denotes the word "participant," and the number refers to the sequence during the interview process, i.e., "P1" refers to the first research participant interviewed by the first author. This was done to prevent research participants' personal information from being identified by others [37, 38]. During the interviews, the first author further invited research participants to provide pictures related to their daily food practices for further discussion and analysis. Moreover, faces in the photographs were blacked out to protect research participants' private privacy.

\section{Data analysis}

With regard to the method and data analysis procedure in this study, the authors apply the constant comparative analysis approach $[39,40]$. Guided by this method, the authors analyzed the data in three steps. First, the authors read each transcript carefully in order to understand the similar and different experiences of home/ethnic food practice behaviors in Belgian Taiwanese immigrant women's daily life. Second, the authors further compared and contrasted the interview data and fieldnotes written by the first author according to the same themes and storylines; in doing so, through the process of constantly comparing and contrasting the transcripts, themes and sub- 
themes would further emerge. Third, after constructing the themes, the authors defined and named these themes and began to compile the research findings. Regarding the issue of how many research participants are sufficient, the criteria that the authors apply in this study was according to the concept of data saturation. Under this standard, the authors stopped interviewing when the participants no longer provided new storylines and information related to the research questions. Accordingly, consistent with the purpose of this study, the themes and storylines are presented and analyzed in the following sections [41] (Table 1).

\section{Analysis and results}

\section{Buying, growing, and making home/ethnic foods in} Taiwanese immigrant women's daily lives

The first challenge that Taiwanese immigrant women may face with regard to making home/ethnic foods, far from their home country and in a foreign land, is obtaining ingredients. Nearly all research participants shared common experiences of going to different Chinese and Asian supermarkets in Brussels, Antwerp, or other Belgian cities in order to buy food ingredients they need. The research participant P7 shared her shopping and food ingredient-finding experiences and also pointed out the difficulty of obtaining adequate food ingredients she needs; this is because the Taiwanese immigrant community in Belgium is small, which reduces the market demand and also supermarket owners' motivation to import foods and ingredients from Taiwan. She said:

I often bought some food and ingredients from Chinese and Asian supermarkets. There are several supermarkets I usually visit, for example, Jin Yuan (金源超市) supermarket in Brussels. If I want to eat some Asian food or want to make some Taiwanese dishes, then I will go there. However, compared to the US where I lived for several years, the number of Taiwanese immigrants in Belgium is quite small. As a result, there are few Taiwanese foods in the Chinese and Asian supermarkets in Belgium. Thus, sometimes it is difficult to find all the foods and ingredients I need for making Taiwanese home/ethnic foods.

Since the Taiwanese immigrant women could not easily find all of the ingredients they wanted at Chinese and Asian supermarkets in Belgium, interestingly, some of the research participants built up their home garden to become a "vegetable farm," where they grow and cultivate some Taiwanese vegetables, spices, and other ingredients that are difficult to obtain from local and Chinese supermarkets. Research participant P1 shared her experiences of growing several different Taiwanese vegetables in her home garden and also discussed what it means to her to grow these "Taiwanese" foods and vegetables in her "Belgian" home garden. She said:

Table 1 Research participants' demographic information

\begin{tabular}{|c|c|c|c|c|}
\hline Code & Age & Year of migration & Family members & Place of residence \\
\hline P1 & 52 & 2000 & Belgian husband, one son & Antwerp \\
\hline P2 & 35 & 2014 & Belgian husband & Brussels \\
\hline P3 & 70 & 1974 & Taiwanese husband, two sons, and one grandchild & Liège \\
\hline P4 & 45 & 2001 & Belgian husband & Brussels \\
\hline P5 & 48 & 1998 & Belgian husband, two sons, and one daughter & Namur \\
\hline P6 & 74 & 1968 & Husband deceased, one daughter, and one grandchild & Brussels \\
\hline P7 & 34 & 2015 & Belgian partner & Brussels \\
\hline P8 & 31 & 2016 & Belgian partner & Louvain-la-Neuve \\
\hline P9 & 50 & 2015 & Belgian husband, one daughter & Brussels \\
\hline P10 & 38 & 2014 & Belgian husband, one son & Bruges \\
\hline P11 & 28 & 2016 & Belgian boyfriend & Antwerp \\
\hline P12 & 57 & 1995 & Belgian husband, two sons & Brussels \\
\hline P13 & 36 & 2014 & Belgian husband, three sons & Ghent \\
\hline P14 & 53 & 1986 & Chinese husband, one son, and one daughter & Leuven \\
\hline P15 & 38 & 2011 & Belgian husband, one daughter & Mol \\
\hline P16 & 29 & 2017 & Belgian boyfriend & Brussels \\
\hline P17 & 45 & 2008 & Belgian husband and two daughters & Leuven \\
\hline
\end{tabular}

Note: "P" denotes the word "participant," and the number refers to the sequence during the interview process, i.e., "P1" refers to the first research participant interviewed by the authors

Source: This study 
In my home garden, there is a special area I called 'Taiwan corner', since I have grown several different vegetables and spices that I brought seeds for from Taiwan, including water spinach (空心菜), sweet potato leaves (地瓜葉), Chinese cabbage (大白菜), and Chinese yam (山藥). You know, since I brought all the seeds of these vegetables from Taiwan to Belgium..., so, every time when I see these vegetables, it brings back my good and childhood memories from my hometown in Taiwan and with my Taiwanese family..., you know, this corner, for me, is like a connection between both of my lives, between Belgium and Taiwan..., very interesting, sometimes, I make video calls using my mobile phone to my elderly parents in Taiwan and share with them about my harvests at the garden, while also sharing with them regarding my life here..., you know, it's like a spaces through which I can make linkages and connections with my Taiwanese family and my home in Taiwan. Moreover, eating these vegetables would further relieve my homesick, and further make me feel comfort.

It is interesting to see that growing different "Taiwanese" vegetables in her home garden has multiple meanings for P1. According to her interview, these vegetables further become "comfort foods" and "nostalgic objects" for her, while eating them has some positive impacts on her psychological condition and wellbeing by reducing her sense of nostalgia, alleviating the pressures of daily life, and letting her feel comfort. In this regard, the meanings of these vegetables for her go far beyond their dietary meanings, as they further become synonymous with "home" and "happiness" for her [42]. It is also important to note that the "Taiwan corner" in P1's home garden does play a vital role of building transnational connection.
By utilizing her mobile phone to video-call her elderly parents in Taiwan, P1 further links her Taiwan life with the Belgian one. Assisting by the use of technology like the mobile phone, which not only makes P1 easily able to learn about her parents' living situations, but also helps her manage the relations with her Taiwanese family through distinct digital and online food-sharing behaviors. In short, these vegetables become a link between P1 and her family in Taiwan; moreover, her online food-sharing behaviors further make her "Taiwan corner" and home garden become an important transnational social space, further allowing her to construct a sense of "online togetherness" between her and family in Taiwan [43-47] (Fig. 1).

Participant P14 also shared her experiences and meanings of making home/ethnic "Taiwanese" foods with her children and husband. P14 further explains why she insists on making "Taiwanese"- or "Chinese"-style foods and dishes for her children and husband, as she believes that the local and Belgian foods are tasteless and unhealthy (Fig. 2). She said:

I usually go to buy the food ingredients from the supermarkets with my children after school. I think my children already have Belgian cuisine for breakfast and lunch, and they have a lot of salad, bread, sandwiches... and for me, I think the traditional Belgian foods are tasteless and unhealthy..., so, I insist on cooking Taiwanese or Chinese styles of foods and dishes for my children for dinner, since I believe that our 'Taiwanese' or 'Chinese' foods taste better and are healthier than the Belgian ones..., moreover, in the food preparing and making procedures, I also like to invite my children to do it with me, and during the process, I will share stories about these Taiwanese or Chinese foods and cuisine cultures with them..., and you know, making these foods with my

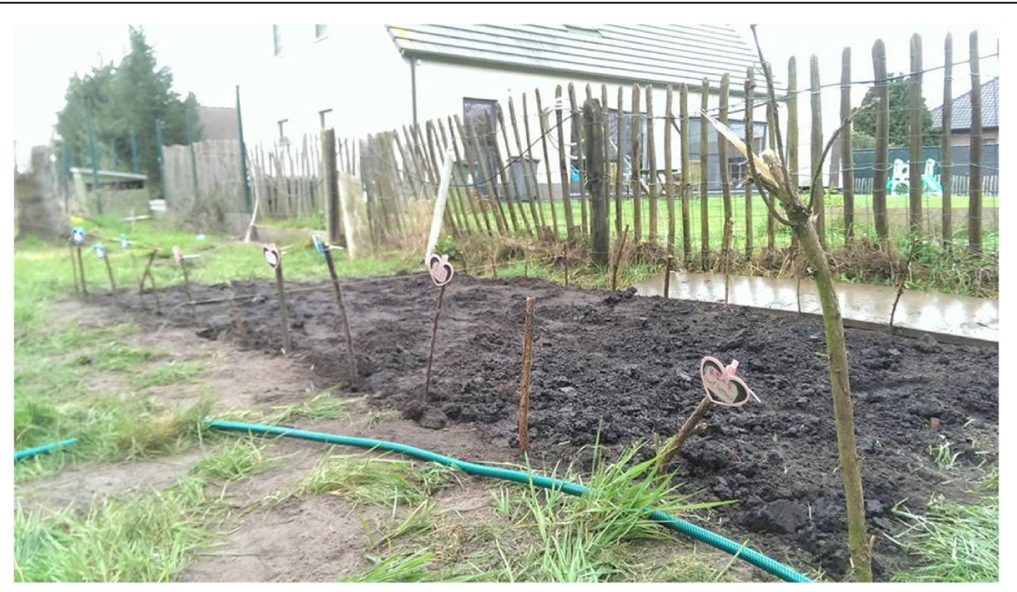

Fig. 1 The "Taiwan corner" in P1's home garden. Source: Provided by P1, with authorization to use 


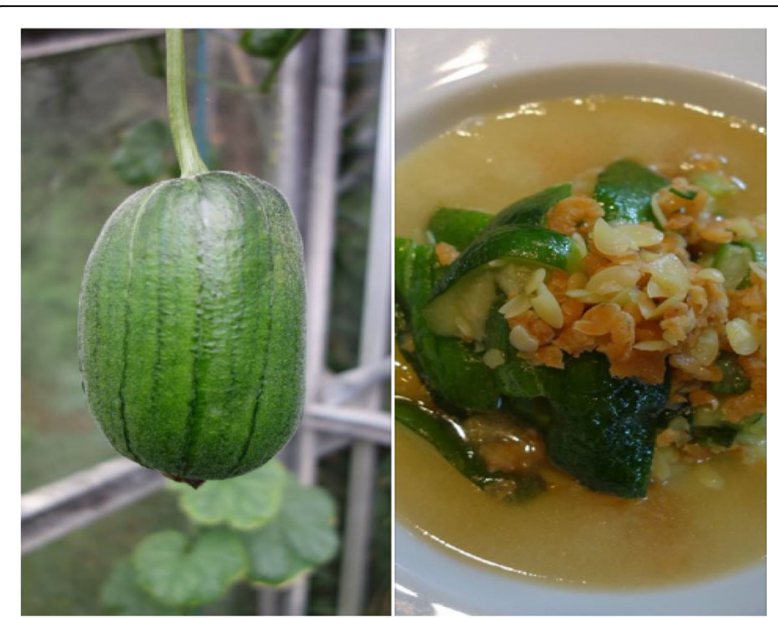

Fig. 2 The luffa growing and the luffa dish made by research participant P14. Source: Provided by P14, with authorization to use

children and husband is quite meaningful for me, which further makes me obtain the "home feelings".

It is true that, according to statistics published in 2015, Belgians have the world's third unhealthiest eating habits, since their foods use too much oil and mayonnaise; moreover, Belgians also eat too many chips in their daily diet [48]. The above statistic shows that P14's worries are reasonable; in this regard, her behavior of insisting on making "Taiwanese"- and "Chinese"-style food for her children in dinner is like a form of compensation. Moreover, by making these home and ethnic foods with her children and husband, she further transfers her food consumption preferences and ethnic food and cultural knowledge horizontally to her children, as well as vertically to her husband. P14's experiences of making food with her children and husband have an additional function of cultural transmission through transferring an immigrant mother's food and dietary habits and ethnic cultural knowledge to the next generation, since immigrant mother plays an important role of "food gatekeeper" to their children by ensuring the foods the children eat are good and healthy $[49,50]$.

\section{Sharing home/ethnic foods with friends and neighbors: an important strategy for expanding and managing friendships in the host society}

In addition to the dimensions of buying, growing, and making home/ethnic foods, sharing Taiwanese home/ ethnic foods with others is another common experience in Taiwanese immigrant women's daily lives. Moreover, this food practice is further regarded as a useful strategy for expanding and cultivating their friendships and social networks in the host society. During the first author's online fieldwork, he saw a social event invitation posted on Facebook by research participant P4 on October 17, 2018. In the post, P4 stated that "I would like to invite my friends to a gathering at my home..., and everyone should take and contribute one dish for sharing..., and I will also organize the activity of Mahjong..., and I will pick you up at the train station". In fact, the first author participated in this event; after the event, the first author invited P4 to participate in the study and the further interview. During the interview, the first author was curious about the reasons why she held this gathering and what it meant to her. In response, $\mathrm{P} 4$ explained:

I really enjoy organizing these activities. Although I don't have a full-time job, I spend the majority of my time on domestic work and family affairs..., however, you know, being a housewife is quite trying..., you don't have much private time for yourself..., sometimes, I really need a break, and I also like to meet old and new friends..., so that is why I posted this information on Facebook to invite my friends to come to my home and gather together for chatting, eating, drinking, and also playing.

Moreover, it is interesting to point out that, based on the first author's participant observation, the majority of the participants in this gathering event were "Taiwanese, " with few "mainland Chinese" immigrants and local Belgians in attendance (the latter were mainly Taiwanese and mainland Chinese women's husbands). Since the attendees were mainly other Taiwanese immigrants, the first author asked P4 about what it meant to her to gather and have fun with these Taiwanese friends. She said:

You know..., actually, I do organize these kind of gathering activities every three to four months..., I think it's quite important to me..., you know, by holding these food-sharing activities, which could help me to escape from my daily and routine life, you know, during the activities, I not only can meet with my old friends, but sometimes, they would bring and introduce new friends to participate in the activities..., so the activities for me have a double effect, at first, I could maintain my friendships with my old friends, but also the activities further enable me to meet new friends..., moreover, since most of the participants here were also Taiwanese immigrants..., so, we did not have any barriers to talk about Taiwan and related issues, and in doing so, it really does make me feel happy and relaxed.

Regularly organizing food-sharing activities became a useful friendship-making and social network cultivation 
strategy for P4, since she not only invites her old friends but also welcomes the participants to introduce new friends to participate in the event. Moreover, her food sharing activities organized at her private house/home also make her home akin to a semi-public space, providing the participants with opportunities to encounter others and make new friends [51] (Fig. 3).

In fact, many other Taiwanese immigrant women share similar experiences to P4: they also hold or participate in food-sharing and eating activities with other Taiwanese immigrant women. Another participant P10 shared her experiences of participating in the foodeating and social gathering activities regularly organized by the virtual community members of "Belgium Taiwanese Wife Chat forum." She further indicated the importance of these food-sharing and social gathering events to her as a Taiwanese immigrant wife and mother living in a foreign land. She said:

...you know, in daily life, I spend the majority of my time taking care of my little children and doing the majority of the domestic work, so I do not have much time for myself..., you may think that [being a] housewife is free and not really busy... that's totally wrong, a housewife actually is pretty busy..., you know, because of that I do not have many friends here [i.e. in Belgium), I just have about five friends in Belgium and they are also Taiwanese immigrant women..., moreover, eating together or sharing food together is the most important entertainment for us..., you know, we have an activity called the "time for Taiwanese mothers", in the event, we will go out or sometimes go to someone's house and eat together..., interestingly, we do have a consensus that "husbands" and "men" cannot participate in the event, we do only welcome immigrant women and housewives...you know, it is super important for me to regularly gather with these Taiwanese immigrant women and housewives, because during the event, we share our different or similar immigrants' life experiences with each other...in doing so, it really makes me feel "I am not alone..., there are still others that have similar experiences to me”,... and the activities also enhance my personal identification with being an immigrant mother and housewife.

From the discussions above, it can be clearly seen that activities involving gathering and eating together are meaningful for these Taiwanese immigrant women and that the food transcends its original materiality and dietary functions. These Taiwanese immigrant women and housewives share the home foods they made with their friends or neighbors, and also regularly participate in activities involving eating and sharing food to which only immigrant wives and mothers are invited; in this regard, food sharing and eating activities take on critical meanings and have various social effects in their immigrant life experiences. For many of the research participants in this study, such as P4 and P10, food-sharing and foodeating activities and behaviors become the important friendship-making and social network cultivation strategies in their immigrant social life. Moreover, the activities of "time for Taiwanese mothers" play further and vital role of constructing the collective social identity of being immigrant wives and mothers in a foreign land, since these events not only effectively reduce immigrant mothers' sense of loneliness, but also assist participants in obtaining useful information and similar experiences shared by others, moreover, making the participants understand that they are not alone and that there are in
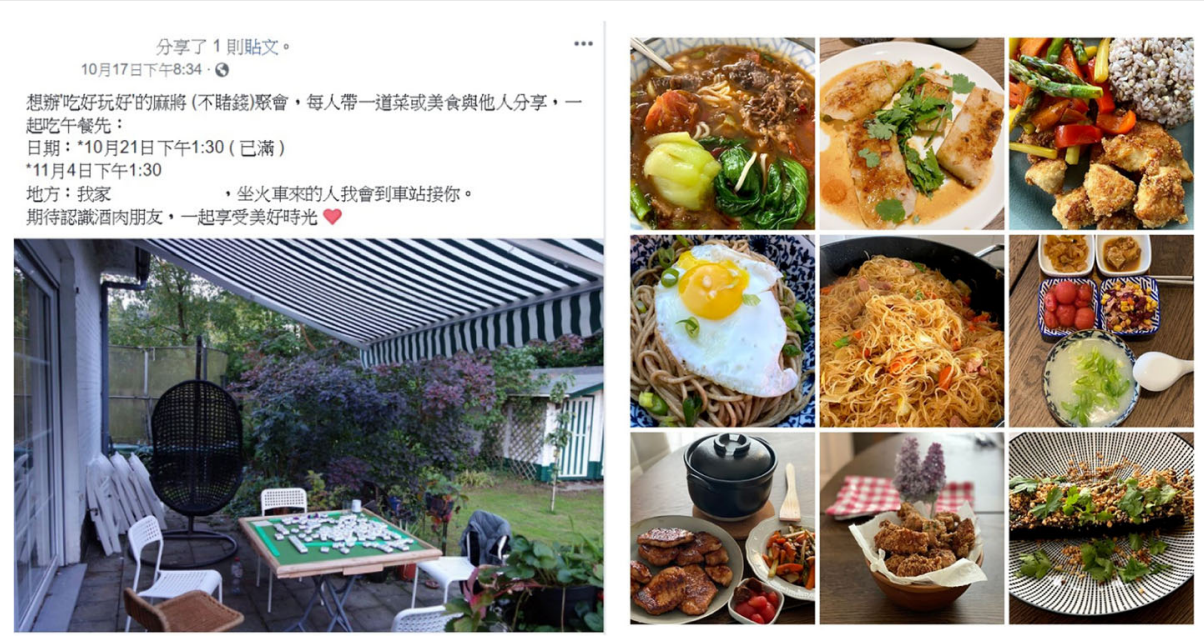

Fig. 3 The information posted by P4 and the dishes brought by the participants. Source: Provided by P4, with authorization to use 
fact many others who share similar social status and lived experiences with them [52, 53] (Fig. 4).

\section{What make foods taste "Taiwanese-style" in the migration context}

It is also very interesting to note that these Taiwanese immigrant women have diverse viewpoints regarding what representative home foods are and what makes foods taste "Taiwanese-style." For example, P12 shared her perceptions regarding the "representative of home/ Taiwanese foods" for her in the migration context. Interesting, the "three cup chicken" (三杯雞) is not only her favorite dish, but also the representative home/Taiwanese food for her (Fig. 5). She said:

...you know, when I was still in Taiwan, my favorite dish was "three cup chicken" (三杯雞)... you know, it smells and tastes so... good, and if you want to cook the 'Taiwanese' style of three cup chicken, you have to put some specific ingredients in..., moreover, as a Taiwanese person, I cook three-cup chicken by frying sesame oil, sugar, Kim Lan soy sauce (金蘭醬油), chili, Asian basil, and chicken legs all together...and very importantly, the soy sauce can only be Kim Lan brand, since this is the only Taiwanese soy sauce I can buy at the Chinese/Asian supermarket in Belgium..., you know, I have to say that the tastes between Kim Lan soy sauce and the soy sauce made in mainland China (老油抽) are really different..., the soy sauces made by mainland China do really taste salty (死鹹), and do not have the soy sauce's original flavor, you know... for me, [the soy sauce made in mainland China] tastes artificial..., so, for me, I insist on using the Kim Lan soy sauce for making three cup chicken has Taiwanese taste.
However, P12 further indicated that she cannot buy all the ingredients she needs; thus, it is quite difficult to make and replicate $100 \%$ "Taiwanese taste" dishes in her immigrant daily life (Fig. 6). She said:

...you know, it is really difficult to replicate one hundred percent 'Taiwanese Taste' in Belgium...you know, at first, it is not easy to find and buy all of the ingredients you need at the Chinese or Asian supermarkets here, since they do have limited foods imported from Taiwan, and moreover, since my husband is a Belgian man, and my children eat Belgian foods in the morning and also in lunch...so, you know, my husband and children, in fact, cannot accept really traditional 'Taiwanese' or 'Chinese' foods..., so, for me, if I want them to accept 'Taiwanese' or 'Chinese' foods, then I have to make some changes, or make it taste like a more Belgian flavor..., so I think because of these two limitations, it is so difficult to say what is real 'authentic Taiwanese' food here. So, I call the foods I make 'TaiwaneseBelgian mixed' dishes.

Another very interesting point is that the research participant P17 insists on using the Ta Tung steam cooker (大同電鍋) to cook rice and make dishes, since from her perspective, this cooker is the only one that can make and replicate foods that taste like the "Taiwanese" style. She said:

... I still remember that, when I decided to emigrate to Belgium many years ago, my Taiwanese mom reminded me to take a Ta Tung steam cooker with me. She said, "A Ta Tung steam cooker can make your foods very easy...", you know, the Ta Tung

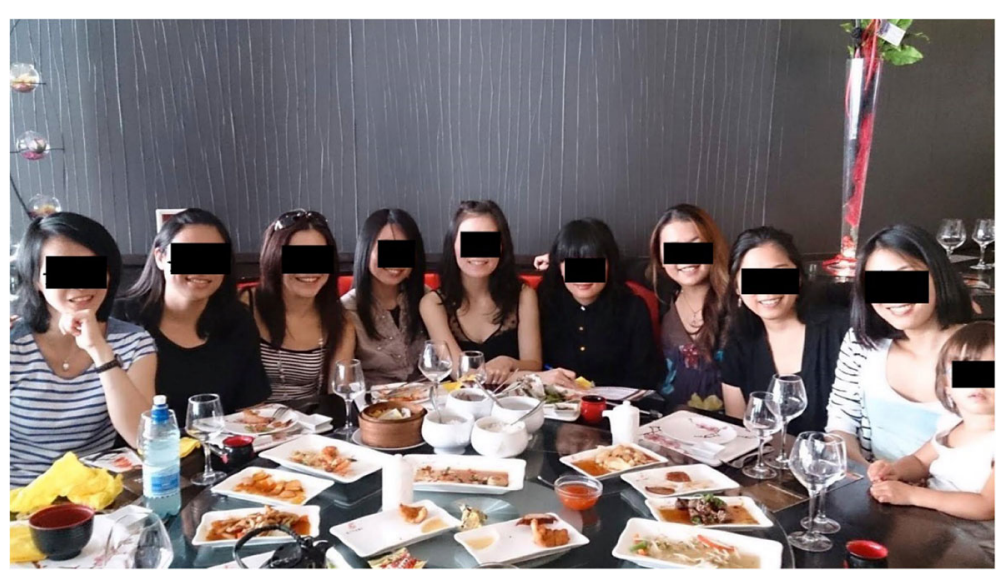

Fig. 4 The food sharing and social gathering activity held by the virtual community "Belgian Taiwanese Immigrant Wives Chat forum." Source: Picture provided by P10, with authorization to use 


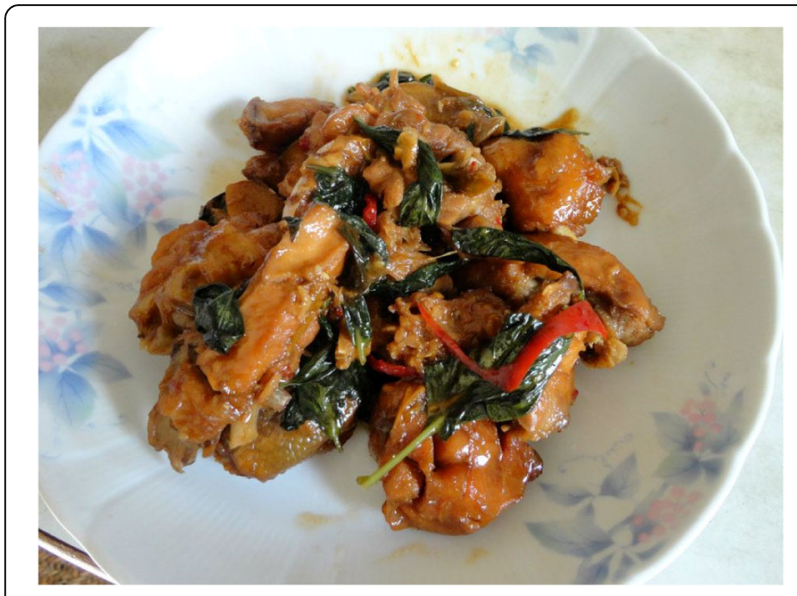

Fig. 5 The "three cup chicken" (三杯雞) cooked by P12. Source: Picture provided by P12, with authorization to use

steam cooker seems like Taiwan's national product. In Taiwan, I can say that more than 90\% of Taiwanese homes do have of this brand of steam cooker..., and you know, it is quite strange that if I use another brand of steam cooker to cook rice or make foods, you know, it tastes less tasty, I don't know why..., but if I use the Ta Tung steam cooker to cook rice or make dishes, the flavors will be good..., I guess maybe it is because we [i.e. Taiwanese people) are used to utilizing this brand of steam cooker to cook rice and make foods.

The above narratives shared by the different research participants clearly show that these immigrant women employ different methods to make the foods and dishes they cook taste "Taiwanese-style." For P12, she insists on using a specific brand of soy sauce to cook her favorite dish, "three cup chicken" (三杯雞); moreover, for P17, she also insists on using the Ta
Tung steam cooker to cook rice or make dishes. Both participants also argued that without adding and using certain specific food ingredients, spices, sauces, or equipment, they cannot make foods that have the "Taiwanese-style" of taste.

It is therefore interesting to point out that these immigrant women use their own and distinct ways to make and define what "Taiwanese" food means for them in the migrant context [54]. Another important point is that, as P12 said, it is also difficult to make and replicate $100 \%$ "Taiwanese-style" foods in her immigrant life; this is because she not only faces difficulty in obtaining adequate Taiwanese food ingredients, but also is required to balance different expectations and preferences regarding taste between herself and her Belgian husband and children. Because of these limitations, it is difficult for her to make a clear and solid definition and interpretation regarding what $100 \%$ authentic "Taiwanese" food is. Thus, for P12, the "Taiwanese-style" foods and dishes she makes in her daily life, in fact, blend Eastern (Taiwanese) and Western (Belgian) tastes. Her narratives regarding the meaning of foods' authenticity and her daily home/ethnic authentic food-making practices clearly demonstrate the fact that the meanings and definitions regarding foods' "authenticity" are not static but rather dynamic and may also change because of people's different living circumstances or distinct taste preferences $[55,56]$. Furthermore, P12's narrative also reveals that her daily food-making and experiences of negotiating different taste preferences within the mixed family have led her to question the notions of "authenticity" and "essentialism" which connected to home/ethnic foods and cultures. This has further caused her to look beyond the idea of cultural essentialism and consequently enabled her to become more open and flexible in navigating and accepting different food tastes and preferences [57].
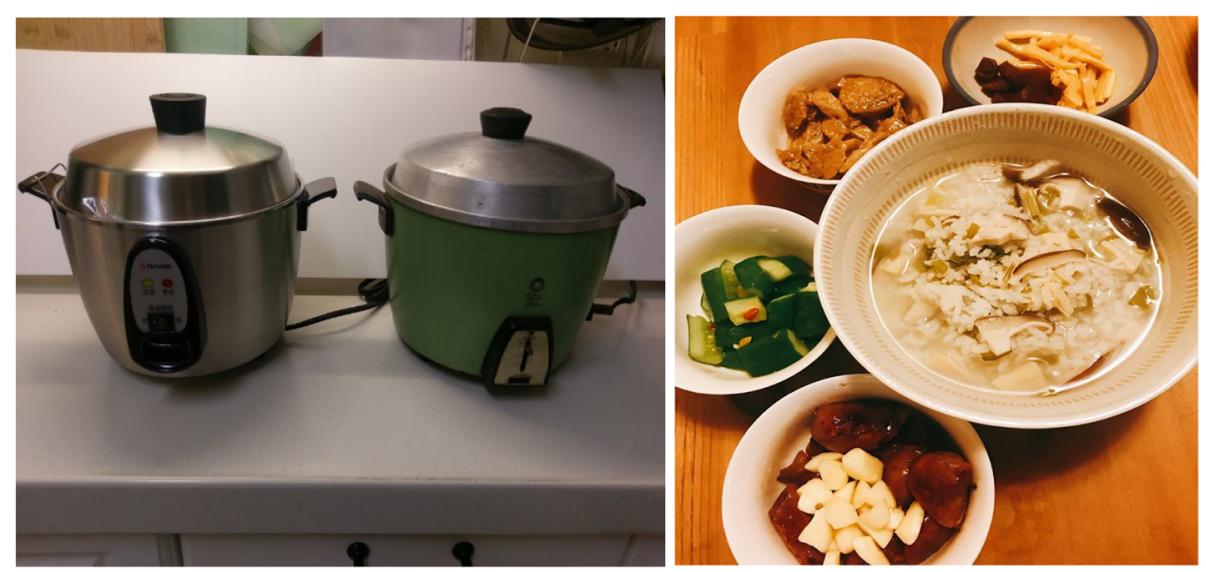

Fig. 6 P17's Ta Tung steam cookers and the foods she made using the cooker. Source: Picture provided by P17, with authorization to use 
Personal memories, ethnonational identity, and cultural markers and the notion of home foods

It is further worth noting that, in the first author's fieldwork and interview experiences, he further found that Taiwanese immigrant women and housewives attach various personal feelings and subjective meanings to the notions of home/ethnic foods in the migrant context. For them, three of the most frequently mentioned attachments in this context are childhood memories, personal ethnonational identity, and certain cultural markers. With regard to personal childhood memories, P5 shared her childhood experiences and discussed the personal meaning of cooking a special dish, "chicken legs and pig ears” (雞腳與豬耳朵), in her immigrant food practices (Fig. 7). She said:

...although I came from Taiwan, and I would identify myself as 'Taiwanese', however, I also belong to the 'Amis' (阿美族) aboriginal ethnic group, so I have the two identities, one is Taiwanese, and the other one is 'Amis', so, if you ask me, "what are the representative Taiwanese foods?" ... Then I will tell you that the dish of 'chicken legs and pig ears' is my favorite 'Taiwanese' food... you know, when I was a child, my family and I lived in the mountain area in Hualien, and I still remember that at the time, my family and parents were still very poor, my parents did not have enough money to buy chicken or pork meat for us, they could only afford to buy the chicken legs and pig ears, the parts that not everyone likes to eat, for feeding us..., now I am living in Belgium, sometimes, when I miss the taste of Taiwanese foods or my Taiwanese family, I will cook this dish and also share it with my Belgian husband and children, interestingly, they also like it quite a lot..., so I will say the representative Taiwanese food and dish for me is the 'chicken legs and pig ears'..., ha, I think it is influenced by my childhood and growth-up experiences.

In addition to the childhood memories, some of the Taiwanese immigrant women connect their ethnonational identity with the notions of home/ethnic foods for them. For example, P3 used a dish called "beef noodles" as an example to explain what Taiwanese food meant to her, as well as her perceptions regarding home foods and her ethnonational identity. She said:

...For me, there is no clear definition of what Taiwanese food is, because I grew up in a 'military dependents' village' (juàn cūn, 眷村) in Taipei, where all the residents came from Mainland China. And our parents were all mainlander migrants, since all of them immigrated to Taiwan accompanied by the Kuomintang (KMT) government, since the KMT and its troops lost the civil war they fought with the Chinese Communist Party (CCP) in 1949..., thus, at the village, the cuisine came from different parts of mainland China, so for me... Taiwanese food and cuisine are quite mixed... like my mixed sense of identity that I identify myself as both 'Chinese and Taiwanese..., and you know, I think the dish of 'beef noodles' is just like me..., this dish actually originates in mainland China, and just like my parents and family, this dish also emigrated from mainland China to Taiwan, taken by the mainlander immigrants at the time...so, in this regard, I will say there is no pure 'Taiwanese' food..., however, the representative Taiwanese food for me is 'beef noodle', and actually it is a mixture of combining mainland Chinese and Taiwanese tastes together, which is similar to the way I identify myself.

Accordingly, it is interesting to point out that Taiwanese immigrant women apply various of different aspects
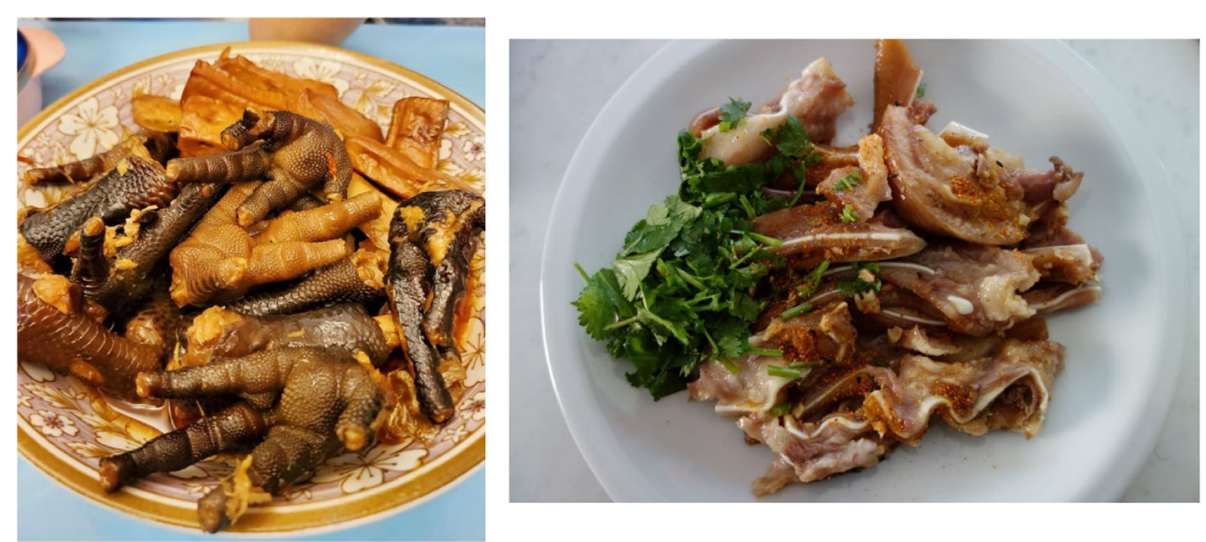

Fig. 7 The "chicken legs and pig ears" dish made by P5. Source: Picture provided by P5, with authorization to use 
to depict the meanings and notion of home/ethnic foods for them. For example, P5 connected her childhood and adolescent memories with the notion of home food. Indeed, P5's narrative and definition regarding the concept of home food for her clearly reflect the truths that food and memory always play vital roles in peoples' ethnic identity construction and belonging formation. Her narrative also reveals that people can create diverse definitions and interpretations regarding the notions of home/ ethnic foods, since everyone has their own and distinct personal lived experiences and memories [58]. Moreover, the narrative shared by P3 further demonstrates how the ways immigrant women define and interpret the meaning and concept of home food are also related to their ethnonational identity and how they identify themselves. For P3, who is affected by her mixed ethnonational identity, the meanings and notions of home foods for her are also quite mixed, since she has a hyphenated identity and identifies herself as "both Chinese and Taiwanese." Accordingly, the representative home food for her is also a food that originated initially from mainland China, subsequently "immigrated" and became famous in Taiwan-the "beef noodles" (牛肉麵) [59]. It is also worthy to note that P5 and P3 have different ethnic backgrounds: P5 has an "Amis" aboriginal ethnic background, while P3's parents immigrated from mainland China to Taiwan when P3 still was a young child, meaning that she has a mainlander (外省人) ethnic background. These different ethnic backgrounds not only influence how they identify themselves, but further cause them to have quite different perceptions regarding the notion of "Taiwanese" foods, as well as distinct viewpoints and preferences with regard to what representative home/ethnic foods are to them. Their narratives further reveal the fact that, since Taiwanese society is constituted by several different ethnic groups, people with different ethnic backgrounds may have quite distinct definitions, viewpoints, and ideas related to the notions of "home/ethnic" foods, or even about Taiwan's national cuisine [60]. Moreover, their narratives further echo the perspective that the notions of "home/ethnic" foods and the concept of "authentic" tastes are both outcomes of social constructions rather than unchangeable or statistical phenomena. This means that people with different personal backgrounds, or who have different living circumstances, have very subjective perceptions and interpretations regarding these issues. Thus, no one can ever fully answer the question as to what authentic and representative "Taiwanese" foods actually are, since these questions will be answered very differently from person to person [55, 57].

Furthermore, although the participants in this study are all women originally from Taiwan, they reveal individual and subjective narratives regarding their distinct ethnonational identity affiliations; moreover, when the authors asked about what makes food "Taiwanese," or about the meaning of making and consuming Taiwanese home/ethnic foods in the context of migrant life, they provided different explanations and divergent interpretations. For the majority of the research participants in the study, their ethnonational identity was majorly related to their self-affiliations with regard to the notions of ethnicity and cultural belonging. For them, the meanings of home or ethnic foods were not only connected to where they came from but were also tied to cultural markers in their daily food practices and lived experiences, especially in mixed-culture families. P15 indicated that she could not eat Belgian food every day and further emphasized that consuming Taiwanese food was important to her; this is not only related to what she likes to eat, but is also a representation of where she came from and who she considers herself is:

...it is quite embarrassing to say that even though I already left Taiwan and lived in Belgium for about a decade, I cannot accept eating Belgian food all day..., you know, Belgians like to eat salad, bread, potato, and fries, and they can eat these foods every day and in every meal ...but I can't, for example, at dinner especially, I definitely want to eat some hot and salty foods, I cannot accept eating salad or bread for my dinner, it's okay for me to eat some cold salad or bread for my breakfast or sometimes for my lunch, but I do not like to eat such foods and dishes for my dinner..., maybe it is because I'm Taiwanese, you know, in Taiwan, we like to eat hot foods rather than cold foods, and we like to eat salty rather than sweet foods..., so you know, almost every day, I prepare two different types of food: Belgian foods, for my Belgian husband and children, and Taiwanese or Chinese foods, and that's for me..., I think it's like a marker that reminds me that I'm still different from Belgians, and I do have pretty different food preferences from them.

P15's narrative shows that, in her mixed-culture home, foods do not only provide people with the necessary nutrition; what people like to eat, and an individual's food preferences, could further become important and obvious cultural and ethnic markers that remind people of their different ethnic backgrounds and cuisine cultures. P15's narrative echoes the anthropologist's perspectives that "we are what we eat." In P15's case, the different food preferences between she and her Belgian husband continue to be vital cultural and ethnic markers reminding her that she still is not $100 \%$ "Belgian"; on the contrary, her 
food preferences and diet habitus are an obvious reflection of her Taiwanese ethnicity [61].

\section{Conclusion}

In this study, the authors chose Taiwanese immigrant women as the research subject and aimed to examine any kind of food practices regarding home foods, as well as to explore the meanings of home/ethnic foods for these women both while living in a foreign country and especially in the migrant context. The study finds that four food practice behaviors are frequently conducted by those immigrant women-buying, growing, eating, and sharing home foods.

Regarding the practice of food buying, the first challenge faced by these Taiwanese immigrant women when making home food in their immigrant lives concern on how to obtain the ingredients they needed. Almost all of the participants in this study have experienced buying food ingredients they needed from Chinese and Asian supermarkets. However, since the Taiwanese immigrant community in Belgium is small both in terms of number and scale, most of the Chinese and Asian supermarkets in Belgium import only limited foods and related ingredients from Taiwan. Accordingly, due to the paucity of food ingredients on sale and difficulty to buy from local supermarkets, some of these immigrant women solve the shortage problem by growing the food ingredients they need in their private home gardens. A number of the immigrant women, in this study, grow several special "Taiwanese" or "Asian" vegetables and spices they brought from Taiwan. Interestingly, these home-grown vegetables and spices do not only act as the supplementary food ingredients for them, but also further transform their private home gardens into transnational social spaces. In these spaces, their home gardens and cultivation behaviors provide them with social and emotional linkage effects that connect their previous life memories and experiences in Taiwan with their present ones in Belgium. Moreover, several participants also like to make home foods together with their husband and especially their children. In the process of making food, immigrant women also like to share the cultural meanings and personal stories behind certain foods; in doing so, they transmit their ethnic cultural values and food preferences horizontally to their husband, as well as vertically to the next generation. Making food together also facilitates intimacy among immigrant family members, which helps Taiwanese immigrant women to (re)create the sense of home and belongings in their immigrant life in Belgium.

The study also found that activities involving sharing and communally consuming food play a vital role in the Taiwanese immigrant women's everyday life. Sharing and consuming Taiwanese foods with immigrant family members, or with other Taiwanese immigrant women and housewives, assist these women in constructing a shared collective and social identity of being Taiwanese immigrants and women/mothers/housewives in Belgium. It is also worth noting that with regard to the question of what makes food have a "Taiwanese-style" taste, the responses shared by the participants were quite varied. For some of the immigrant women, specific sauces and spices could help them to replicate the "Taiwanese-style" taste, while others believe that the Ta Tung steam cooker plays an important role in enabling them to cook "Taiwanese-style" food in their daily food practices.

However, participants were also limited by ingredient shortages in the host society, as well as by their family members' unwillingness to totally accept Taiwanese foods or "Taiwanese-style" foods. Both of these issues required the Taiwanese immigrant women to negotiate further, and sometimes to compromise regarding what constitutes "authentic" Taiwanese food and what such "authentic" food tastes like. Furthermore, the definitions and meanings of Taiwanese food in these immigrant women's daily lives and international journeys vary from person to person, affected by factors ranging from personal childhood memories to dual identity and cultural and ethnic markers.

Overall, this study has demonstrated that in order to make original home foods in their everyday lives in Belgium, Taiwanese immigrant women must face and deal with a series of challenges and difficulties, ranging from obtaining adequate ingredients to negotiating the concept of authentic taste. The study participants consequently developed different strategies to overcome these obstacles, which include buying, growing, making, and sharing foods. In addition to these practical food practice strategies adopted by the Taiwanese immigrant women, home or Taiwanese ethnic foods have other social and psychological effects in their lives, from assisting them in making new friends while expanding and cultivating their interpersonal social networks to allowing them to construct a collective and social identity of being Taiwanese immigrant women, mothers, and housewives in a foreign land.

Regarding the study's limitations, as most of the research participants were first-generation Taiwanese immigrant women living in Belgium, there is a lack of voices from the other generations. However, since the literature has already demonstrated that different generations of immigrants have distinct perceptions regarding the notions of home or ethnic foods (Weller \& Turkon, 2015) [13], the authors suggest that future research could further explore the meaning of home or ethnic foods among different generations of Taiwanese immigrants, as this would enable a deeper and more complete understanding of intergenerational perspectives to be gained. 


\section{Acknowledgements}

The authors would like to acknowledge and appreciate all research participants in this study for their contribution in sharing their views and life stories.

\section{Author details}

Hsien-Ming Lin is a PhD candidate, affiliated with both the Doctoral Program of Social and Cultural Anthropology, Interculturalism, Migration and Minorities Research Centre, KU Leuven, and the Institute of Political Science, National Sun Yat-sen University.

Ching Lin Pang is an Associate Professor, affiliated with both the Faculty of Art Department of Applied Linguistics, University of Antwerp; and Interculturalism, Migration, and Minorities Research Centre, KU Leuven. Da-Chi Liao is a Distinguished Professor, affiliated with the Institute of Political Science, National Sun Yat-sen University.

\section{Authors' contributions}

The fieldwork and interviews were conducted by the first author. However, three authors contributed equally to the manuscript and revisions. All of the authors approved the final manuscript.

\section{Funding}

The article is based on an independent research self-funded by the authors,

\section{Availability of data and materials}

Not applicable.

\section{Competing interests}

The authors declare that they have no competing interests.

\section{Author details}

${ }^{1}$ Faculty of Social Science, Katholieke Universiteit Leuven, Leuven, Belgium. ${ }^{2}$ Institute of Political Science, National Sun Yat-sen University, Kaohsiung, Taiwan. ${ }^{3}$ Faculty of Art Department of Applied Linguistics, University of Antwerp; and Interculturalism, Migration and Minorities Research Centre, KU Leuven, Leuven, Belgium. ${ }^{4}$ Institute of Political Science, National Sun Yat-sen University, No.70 Lien-hai Rd., Kaohsiung, 80424 Kaohsiung, Taiwan.

\section{Received: 23 January 2020 Accepted: 4 August 2020}

\section{Published online: 01 September 2020}

\section{References}

1. Ore H. Ambivalent nostalgia: Jewish-Israeli migrant women "cooking" ways to return home. Food Cult Soc. 2018;21(4):568-84.

2. Gu CJ. Women's Status in the Context of International Migration. Sociol Compass. 2012;6(6):458-71

3. Bove CF, Sobal J, Rauschenbach BS. Food choices among newly married couples: convergence, conflict, individualism, and projects. Appetite. 2003; 40(1):25-41.

4. D'Sylva A, Beagan BL. Food is culture, but it's also power': the role of food in ethnic and gender identity construction among Goan Canadian women. J Gend Stud. 2011:20(3):279-89.

5. DeVault M. Feeding the family: the social organization of caring as gendered work: University of Chicago Press; 1991.

6. Morgan DHG. Family connections: an introduction to family studies: Polity Press; 1996.

7. Seto-Suh E. Everyday practices of immigrant Vietnamese women in Japan in obtaining ingredients for the food of their homeland. In: ljichi N, Kato A Sakurada R, editors. Rethinking Representations of Asian Women. New York: Palgrave Macmillan; 2016. p. 69-85.

8. Vignolles A, Pichon P-E. A taste of nostalgia: Links between nostalgia and food consumption. Qual Market Res. 2014;17(3):225-38.

9. Gunew S. Introduction: Multicultural translations of food, bodies, language. J Intercult Stud. 2000;21(3):227-37.

10. Duruz J. Living in Singapore, travelling to Hong Kong, remembering Australia: intersections of food and place. J Aust Stud. 2006;30(87):101-15.

11. Lin JH, Chang CW, Chi HC. Transnational bubbles making taiwanese bubble tea in the UK. J Geogr Sci. 2017:87:1-20

12. Kershen AJ. Introduction: food in the migrant experience. In: Kershen AJ, editor. Food in the migrant experience. London: Routledge; 2002. p. 1-13.
13. Weller DL, Turkon DS. Contextualizing the immigrant experience: the role of food and foodways in identity maintenance and formation for first- and secondgeneration Latinos in Ithaca, New York. Ecol Food Nutr. 2015;54(1):57-73.

14. Tse L. Resisting and reversing language shift: heritage-language resilience among U.S. native biliterates. Harv Educ Rev. 2001;71(4):676-709.

15. Schermuly AC, Forbes-Mewett $\mathrm{H}$. Food, identity and belonging: a case study of South African-Australians. Br Food J. 2016:118(10):2434-43.

16. Liu Y H, Pang C L. Homing the city - cross-scale exploration of negotiating the idea of home by Chinese women in Antwerp. In: 2019 Displacement and domesticity refugee, migrants and expats making homes conference, KU Leuven Brussel Campus.

17. Wang FC. From Chinese original domicile to Taiwanese ethnicity: an analysis of census category transformation in Taiwan. Taiwan Sociol. 2005;9:59-117.

18. Hsieh KP. The Development of ethnic studies in Taiwan. J Taiwan Indigenous Stud Assoc. 2011;1(1):1-27.

19. National Chengchi University. Changes in the Taiwanese/Chinese identity of Taiwanese. https://esc.nccu.edu.tw/app/news.php?Sn=166. Accessed 19 Jan 2020.

20. Chuang HT. The rise of culinary tourism and its transformation of food cultures: the national cuisine of Taiwan. Copenhagen J Asian Stud. 2009; 27(2):84-108.

21. Overseas Community Affairs Council. The number of overseas Taiwanese. https://www.ocac.gov.tw/OCAC/Pages/VDetail.aspx?nodeid=58\&pid=492837. Accessed 28 Jan 2020

22. Lin HM. The Theoretical concept of super-diversity and research implications. J Population Stud. 2018:57:79-123.

23. Pang CL. Business opportunity or food pornography? Chinese restaurant ventures in Antwerp. Int J Entrep Behav Res. 2002;8(1):148-61.

24. Taipei Representative Office in the EU and Belgium. The number of taiwanese immigrants in Belgium. https://www.taiwanembassy.org/be/ post/509.html. Accessed 11 Feb 2020.

25. Geldof D. Superdiversity in the heart of Europe. How migration changes our society: ACCO; 2016

26. Pang CL. Invisible visibility: intergenerational transfer of identity and the social position of Chinese women in Belgium. Asian Pac Migr J. 1998;7(4): 433-52.

27. Pang CL. Gateways to the urban economy: Chinatowns in Antwerp and Brussels. In: Aytar V, Rath J, editors. Selling Ethnic Neighborhoods. The Rise of Neighborhoods as Places of Leisure and Consumption. London: Routledge; 2012. p. 52-68.

28. Gu CJ. Resilient self: gender, immigration, and Taiwanese Americans: Rutgers University Press; 2017.

29. Gatti E. Defining the Expat: the case of high-skilled migrants in Brussels. Brussels Stud. 2009:28:1-15.

30. O'Reilly K, Benson M. Lifestyle migration: escaping to the good life? In: Benson M, O'Reilly K, editors. Lifestyle migration: expectations, aspirations and experiences. Aldershot: Ashgate; 2009. p. 1-13.

31. Common-Wealth Magazine. How much money could I earn from working holiday? Let the statistical data tell you. https://www.cw.com.tw/article/ article.action?id=5077596. Accessed 22 Sept 2019.

32. Bowler GM. Netnography: a method specifically designed to study cultures and communities online. Qual Rep. 2010;15(5):1270-5.

33. Dalsgaard S. The ethnographic use of Facebook in everyday life. Anthropol Forum. 2016:26(1):96-114.

34. Kozinets RV. The field behind the screen: using netnography for marketing research in online communities. J Mark Res. 2002:39(1):61-72.

35. Kozinets RV. Marketing Netnography: Prom/ot (Ulgat) ing a new research method. Methodol Innov Online. 2012;7(1):37-45.

36. Hsu HP, Pang CL, Haagdorens W. Writing as Cultural Practice: Case study of a Chinese Heritage School in Belgium. Procedia Soc Behav Sci. 2012:47:1592-6.

37. Diefenbach T. Are case studies more than sophisticated storytelling? Methodological problems of qualitative empirical research mainly based on semi-structured interviews. Qual Quan. 2008:43:875-49.

38. Saunders BKJ, Kitzinger C. Anonymising interview data: challenges and compromise in practice. Qual Res. 2015;15(5):616-32.

39. Glaser BG. The constant comparative method of qualitative analysis. Soc Probl. 1965:12(4):436-45.

40. Kolb SM. Grounded theory and the constant comparative method: valid research strategies for educators. J Emerg Trends Educ Res Policy Stud. 2012;3(1):83-6.

41. Nowell LS, Norris JM, White DE, Moules NJ. Thematic analysis striving to meet the trustworthiness criteria. Int J Qual Methods. 2017;16:115-60. 
42. Locher JL, Yoels WL, Maurer D, van Ells J. Comfort foods: an exploratory journey into the social and emotional significance of food. Food Foodways. 2005;13(4):273-97.

43. Head LM, Muir P, Hampel E. Australian backyard gardens and the journey of migration. Geogr Rev. 2004;94(3):326-47.

44. Li WW, Hodgetts D, Ho E. Gardens, transitions and identity reconstruction among older Chinese immigrants to New Zealand. J Health Psychol. 2010; 15(5):786-96.

45. Gerodetti N, Sally F. Growing foods from home: food production, migrants and the changing cultural landscapes of gardens and allotments. Landsc Res. 2016:41(7):808-19.

46. Marino, S. Making Space, Making Place: Digital Togetherness and the redefinition of migrant identities online. Social Media + Society. 2015.

47. Marino S. Digital food and foodways: how online food practices and narratives shape the Italian diaspora in London. J Mater Cult. 2018;23(3):263-79.

48. vrt NEWS. Belgians have world's third unhealthiest eating habits. https:// www.vrt.be/vrtnws/en/2015/02/21/_belgians_have_ worldsthirdunhealthiesteatinghabits-1-2246119/. Accessed 16 Feb 2020.

49. Bailey A. The migrant suitcase: food, belonging and commensality among Indian migrants in The Netherlands. Appetite. 2017;110(1):51-60.

50. Nakamura LM. Food choices in mixed families. In: Mixed family life in the UK. Palgrave Macmillan Studies in Family and Intimate Life: Palgrave Macmillan; 2017

51. Marovelli B. Cooking and eating together in London: food sharing initiatives as collective spaces of encounter. Geoforum. 2019;99:190-201.

52. Vallianatos $H$, Raine K. Consuming food and constructing identities among Arabic and South Asian immigrant women. Food Cult Soc. 2008;1 1(3):355-73.

53. Brown L, Paszkiewicz I. The role of food in the Polish migrant adjustment journey. Appetite. 2017;109(1):57-65.

54. Sifton L. A Taste of Taiwan. https://www.nytimes.com/2015/06/14/ magazine/a-taste-of-taiwan.html. Accessed 7 Feb 2020.

55. Pang CL. Beyond authenticity: reinterpreting Chinese immigrant food and Belgium. In: Doring T, Heide M, Muhleisen S, editors. Eating Culture. The Poetics and Politics of Food. Heidelberg: Heidelberg University Press; 2003. p. 53-70.

56. Bardhi F, Ostberg J, Bengtsson A. Negotiating cultural boundaries: food, travel and consumer identities. Consum Mark Cult. 2010;13(2):133-57.

57. Lu S, Fine G. The presentation of ethnic authenticity: Chinese food as a social accomplishment. Sociol Q. 1995;36(3):535-53.

58. Abarca ME, Colby JR. Food memories seasoning the narratives of our lives. Food Foodways. 2016;24(1-2):1-8.

59. Mok, T. Consuming culture: food and the shaping of Asian American identity. https://hyphenmagazine.com/blog/2019/08/consuming-culturefood-and-shaping-asian-american-identity. Accessed 13 Jan 2020.

60. Chen YJ. Ethnic politics in the framing of national cuisine. Food Cult Soc 2011;14(3):315-33.

61. Mintz S, Christine MDB. The anthropology of food and eating. Annu Rev Anthropol. 2002;31:99-119.

\section{Publisher's Note}

Springer Nature remains neutral with regard to jurisdictional claims in published maps and institutional affiliations.

Ready to submit your research? Choose BMC and benefit from:

- fast, convenient online submission

- thorough peer review by experienced researchers in your field

- rapid publication on acceptance

- support for research data, including large and complex data types

- gold Open Access which fosters wider collaboration and increased citations

- maximum visibility for your research: over $100 \mathrm{M}$ website views per year

At $\mathrm{BMC}$, research is always in progress.

Learn more biomedcentral.com/submissions 